\title{
Trials are already being prioritised, just not at the institutional level
}

\section{Simon Kolstoe}

Successful clinical trials are important for all of us, but they can be extremely complicated to design and run, so work must be done to consider what commonly goes wrong and how these issues can be addressed. Gelinas et al suggest an ethical argument for institutional prioritisation of clinical trials conducted among limited populations. This is to ensure successful recruitment and prevent competing trials rendering each other irrelevant through lack of statistical power. But they overlook the fact that effective prioritisation already occurs, and their suggestion produces yet another hurdle for researchers to overcome.

Their argument hinges around the claim that allocation of participants to trials represents an inevitable rationing scenario and, like all rationing scenarios, the best methods should be used for objectively determining how limited resources (participants) are distributed to achieve the end goal (successful clinical trials). ${ }^{1}$ Although they acknowledge that both individuals and clinicians may have preferences as to which trial a patient participates in, trial interventions are by definition experimental, and therefore choosing between trials is not really analogous to choosing between alternative clinical interventions. Here it seems that although clinical instinct is important when determining treatment options, a clinical trial is a specific attempt to create systematic justified knowledge and thus individual patient/clinician autonomy is not particularly relevant. They also argue that neither randomisation (determining which trials should be able to recruit first by flipping a coin) nor the prioritisation of the wealthiest trials represents sound ways to determine which trials should be prioritised. These are important and valuable arguments.

Gelinas et al also seem mostly correct in arguing that a fundamental tenet in research ethics is justified by risk-benefit

Institute of Biomedical and Biomolecular Science, Portsmouth, UK

Correspondence to Dr Simon Kolstoe, Institute of Biomedical and Biomolecular Science, King Henry Building, Portsmouth P01 2DY, UK; simon.kolstoe@ port.ac.uk ratio. If a trial does not recruit adequately, there is no overall social benefit to balance the risks taken by participants already recruited on the trial. However, they are too quick to state that benefit for a small number of participants can never justify a trial. They seem overly enamoured with the more traditional 'blockbuster' model of drug development without fully appreciating that drugs or treatments may have very different effects in small and subtly different populations. Indeed, a number of fruitful research avenues (such as pharmacogenetics) include combing through data from apparently 'failed' trials to work out if drugs or treatments might be successful in subpopulations. ${ }^{2}$ A second pertinent issue is that failed trials may produce valuable methodological lessons that will benefit the trials community. ${ }^{3}$ Gelinas et al are therefore not correct when they argue that underpowered or under-recruited trials never produce benefits to offset risks to participants.

The paper makes the suggestion that trials should be prioritised on an institutional basis by either limiting the number of trials that can be open for recruitment at any one time or creating a rank order of trials where those at the top of the list get first access to the patients who are only told about subsequent trials if they decline to participate in the first ranked trial. The authors acknowledge that the issue of how to rank trials is not straightforward, and indeed almost immediately seem to contradict an earlier part of their argument by stating that sometimes it may be ethically justified to give potential participants the choice between a high risk, but potentially high reward trial, and a low risk but low reward trial. However, to be charitable, this is within the context of giving two trials an equal rank when there are multiple possible trials.

They then argue that so long as institutions use a transparent and consistent system to prioritise trials such a system would be fair to participants, investigators and funders. For participants, although patient-participant involvement (PPI) is an important and increasing priority in trial design, ${ }^{4}$ there is no apparent positive moral right to have all possible trials made available to every patient. Indeed, sometimes limiting trial options may be ethically preferable both to help avoid therapeutic misconception and avoid the possibility of very sick patients or their relatives blaming themselves for choosing the wrong trial. For investigators or their funders, while they are perhaps most likely to complain that an institutional allocation system is unfair if it does not prioritise their particular study, it is not beyond the realms of administrative possibility to coordinate efforts between funders, investigators and institutions at the earlier planning stages of projects to ensure that a fair and workable solution is produced.

Although it is no doubt helpful to have arguments such as these rehearsed, Gelinas et al seem to overlook the fact that trial prioritisation already occurs. Granted individual institutions seldom have the systems that the authors advocate, and it is no doubt frustrating for investigators based at small institutions with limited participant populations, but large drug trials are almost always multicentre if not multinational and are substantially ranked and prioritised within companies, funding agencies or clinical trial units. Such prioritisation already proceeds more or less as described by the authors, relying initially on peer review, then taking into account social (or market) benefits, and sometimes even undergoing international coordination such as seen during the recent Ebola outbreak. ${ }^{5}$ Furthermore, clinicians frequently communicate with each other, and while the problem of incentives should never be ignored, the clinical research community is a place of rigorous debate with clinicians often coordinating efforts informally. Even research ethics committees consider the issue of adequate recruitment, asking investigators how big recruitment pools are and how many other studies are currently recruiting from the same pool prior to giving a favourable opinion. Although it may never be possible to entirely eradicate the problem of trial under-recruitment, and certainly local or regional studies are most likely to run into problems, the issue of underrecruitment is already well appreciated within the trial community. Proposing additional prioritisation or ranking schemes at an institutional level will simply produce yet another level of bureaucracy in an already arguably overlegislated area of research.

Competing interests None declared. 
Provenance and peer review Commissioned; internally peer reviewed.

\section{(6) \\ OPEN ACCESS}

Open Access This is an Open Access article distributed in accordance with the Creative Commons Attribution Non Commercial (CC BY-NC 4.0) license, which permits others to distribute, remix, adapt, build upon this work non-commercially, and license their derivative works on different terms, provided the original work is properly cited and the use is non- commercial. See: http://creativecommons.org/licenses/ by-nc/4.0/

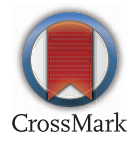

To cite Kolstoe S. J Med Ethics 2017:43:814-815.

Received 28 October 2016

Accepted 19 January 2017

Published Online First 6 February 2017

$J$ Med Ethics 2017;43:814-815.

doi:10.1136/medethics-2016-104000

\section{REFERENCES}

1 King D, Maynard A. Public opinion and rationing in the United Kingdom. Health Policy 1999;50:39-53.

2 Spear BB, Heath-Chiozzi M, Huff J. Clinical application of pharmacogenetics. Trends Mol Med 2001;7:201-4.

3 Carlsson CM. Lessons learned from failed and discontinued trials for the treatment of Alzheimer's disease: future directions. J Alzheimers Dis 2008;15:327-38.

4 Bagley HJ, Short H, Harman NL, et al. A patient and public involvement (PPI) toolkit for meaningful and flexible involvement in clinical trials-a work in progress. Res Involv Eng 2016;2:15.

5 European Union. Global overview of Ebola research, March 2015. https://ec.europa.eu/research/health/pdf/ ebola_research_overview.pdf (accessed 28 Oct 2016). 